\title{
Determinants of Proteinuria among Type 2 Diabetic Patients at Shakiso Health Center, Southern Ethiopia: A Retrospective Study
}

\author{
Girum Tefera \\ Tehran University of medical sciences, Department of Medical Biotechnology, Iran
}

Copyright (C) 2015 Horizon Research Publishing All rights reserved.

\begin{abstract}
Diabetic nephropathy is the leading cause of end stage kidney disease among type 2 diabetics worldwide. Proteinuria has been noted to be the cardinal symptom of progressive loss of renal function. This study examined the impact of duration of diabetes, demography (age, gender) and metabolic factors on the frequency of proteinuria among type 2 diabetics visiting Shakiso health center. In this Institution based retrospective study700 type 2 diabetics aged between25-65years result were analyzed from July 2013 to July 2014 and parameters estimated include fasting blood glucose (FBS), body mass index (BMI), urine protein and blood pressure. Proteinuria among the study cohorts was graded no proteinuria, mild proteinuria to heavy proteinuria. The frequency of proteinuria for the varied grades in type 2 diabetics enrolled in the study ranged from $73.3 \%$ (no proteinuria), $15.2 \%$ (mild proteinuria) and $15.6 \%$ (heavy proteinuria). $1(100 \%)$ patient with heavy proteinuria presented with grade 3 hypertension; and $4(33.3 \%)$ and $11(20.8 \%)$ patients presented with grade 1 and isolated systolic hypertension respectively. Multiple logistic regression analysis showed study participants with duration of diabetes ranging from $11-15$ years $(\mathrm{OR}=2.8 ; 95 \%$ $\mathrm{CI}=1.1-7.2 ; \mathrm{p}=0.028)$ and $16-20$ years $(\mathrm{OR}=5.6 ; 95 \%$ $\mathrm{CI}=1.4-22.5 ; \mathrm{p}=0.016)$ were at an increased risk of proteinuria. The frequency of nephropathy is promoted independently by advanced age, hypertension and duration of diabetes.
\end{abstract}

Keywords Proteinuria, Type 2 Diabetes, Obesity, Hypertension, Shakiso Health Center

\section{Introduction}

Diabetes mellitus is a clinical syndrome associated with insulin deficiency, inefficiency or both (Harris and Zimmet, 1997). The world health organization (WHO) estimates that over 170 million people worldwide are presenting with diabetes with the number possibly rising to 370 million in the next 20 years (USRD, 2004). One of the complications of type 2 diabetes mellitus (T2DM) is nephropathy characterized by increased excretion of protein in the urine which is presently the leading attributable cause of chronic kidney disease (CKD) (USRD, 2004).

To date, there is a paucity of information on proteinuria (macro albuminuria) among type 2 diabetics in Shakiso; however, studies conducted in Nigeria and other African countries have reported highly varying prevalence rates ranging from as low as $7.0 \%$ to $82.5 \%$ (Lutaleet al., 2007; Balogun and Abbiyesuku, 2011).

Several studies have concluded that factors such as age, gender, diet and obesity, hypertension and proteinuria influence the progression of diabetic nephropathy (Rossinget al., 2004; Leeheyet al., 2005; Imai et al., 2008). Subsequently, glycemic control and the Reno protective effect of angiotensin converting enzyme inhibitors and blockers on proteinuria have been identified as factors that influence proteinuria in T2DM (Klahret al., 1994; Peterson et al., 1995; Mandal and Hiebert, 2008). The interplay of these factors in the development and progression of proteinuria and subsequent diabetes associated nephropathy among diabetics who attend at Shakiso health center has not been well elucidated. This study therefore examined the impact of age, obesity, hypertension, blood glucose concentration and duration of diabetes on the frequency of proteinuria among T2DM patients.

\section{Materials and Methods}

\subsection{Study Design}

The present retrospective study was conducted at Shakiso health center in Shakiso town, Southern Ethiopia. Institution based retrospective study design was used and the data's of all type 2 diabetic patients those with protein in the urine who visited the health center from July 2013 to July 2014 
were considered for the study.

\subsection{Study Area}

The study was conducted from July 2013 to July 2014 at Shakiso health center. It is located on the road connecting Addis Ababa to Nairobi in the Southern Region of Ethiopia. The

Latitude of Shakiso, is 5.883 and its Longitude is 38.97 .

The 2007 national census reported a total population for this woreda of 206,372 , of whom 107,224 were men and 99,148 were women; 33,643 or $16.3 \%$ of its population were urban dwellers. The majority of the inhabitants said they were Protestant, with $56.64 \%$ of the population reporting they observed this belief, while $14.07 \%$ of the population practiced Ethiopian, $11.4 \%$ were Muslim, $10.69 \%$ practiced traditional beliefs, and $1.86 \%$ were Catholic.

\subsection{Study Subjects}

A total of 700 subjects comprising 502 females and 198 males with ages ranging from 25-65years were selected from Shakiso health center. All patients involved in this report were provided a written informed consent prior to data collection. Furthermore, written informed consent was obtained from each patient for publication

\subsection{Inclusion Criteria}

All type 2 diabetics with ages ranging from 25 years and who were on hypoglycemic agents or on diet therapy, but not on insulin therapy were enrolled into the study. Confirmation of diagnosis was made from patient folders before being recruited into the study.

\subsubsection{Exclusion Criteria}

Type 1 diabetics and type 2 diabetics undergoing any form of dialysis were excluded from the study. Diabetics on insulin therapy were excluded from the study.

\subsection{Blood Sample Collection}

Two milliliters $(2 \mathrm{ml})$ of venous blood was drawn from each study participant after an overnight fast (12-14 hours) and dispensed into fluoride oxalate tubes. After centrifugation at $1500 \mathrm{~g}$ for 3 minutes, the plasma was aliquoted into cryovials and stored at $-80^{\circ} \mathrm{C}$ until assayed.

\subsection{Fasting Blood Sugar}

This was estimated using the glucose oxidase/peroxidase method (Trinder, 1969) and the color developed was measured with a spectrophotometer [(Spectronic-20), 820 Linden Avenue, Rochester, NY 14625, USA] at a wavelength of $500 \mathrm{~nm}$.

\subsection{Urine Collection and Estimation of Urine Protein}

Early morning urine samples collected into clean, wide mouth and leak proof containers were obtained from the participants and preserved with boric acid $(0.1 \mathrm{~g})$ for every $10 \mathrm{ml}$ of urine. Proteinuria (semi-quantitative) was assessed using dip-stick (CYBOW ${ }^{\mathrm{TM}}$ DFI Co Ltd, Gimhae-City, Republic of Korea) and confirmed with the sulphosalicylic acid method. Proteinuria was defined as none when the dipstick test turns out negative; mild for dipstick results ranging from trace to $1+$ and heavy for dipstick results ranging from $2+$ to $4+$.

\subsection{Anthropometric Variables}

Height to the nearest centimeter without shoes was measured with a wall-mounted ruler and weight to the nearest $0.1 \mathrm{~kg}$ in light clothing was measured using a bathroom scale (Zhongshan Camry Electronic Co. Ltd, Guangdong, China). Body mass index (BMI) was calculated by dividing weight $(\mathrm{kg})$ by height squared $(\mathrm{m} 2)$.

\subsection{Blood Pressure (using Krotkoff 1 and 5)}

Blood pressure was measured by trained personnel using a mercury sphygmomanometer and a stethoscope. All measurements were in accordance with recommendations of the American Heart Association (Kirkendall et al., 1967). Mean values of duplicate measurements were recorded as the blood pressure. Hypertension was graded as normal when the systolic blood pressure (SBP) is less than $120 \mathrm{~mm} \mathrm{Hg}$ and diastolic blood pressure (DBP) is less than $80 \mathrm{~mm} \mathrm{Hg}$; pre-hypertension: $\mathrm{SBP}=120-139$ or $D B P=80-89$; Stage 1 hypertension: $\mathrm{SBP}=140-159$ or $\mathrm{DBP}=90-99$; Stage 2 hypertension: SBP $>160$ or $D B P>100$ (Chobanianet al., 2003).

\subsubsection{Calculation of Mean Arterial Pressure (MAP)}

The mean arterial pressure was estimated using the formula:

$$
\mathrm{MAP} \approx \mathrm{DP}+\underline{(\mathrm{SP}-\mathrm{DP})}
$$

\section{Statistical Analysis}

Results are expressed as means $\pm \mathrm{SD}$. Unpaired $t$-test was used to compare mean values of continuous variables and $\chi 2$ test statistic was used to compare all categorical variables. For all statistical comparisons, a p-value $<0.05$ was considered as statistically significant. Multivariate logistic regression was used to estimate the odds ratios of risk factors of proteinuria after adjusting for age and sex. GraphPad Prism version 5.00 for windows (GraphPad software, San Die-go California USA, www.graphpad.com) and SYS-TAT version 12 (SYSTAT software, 239 Western Street, Suite F Fairfield, CA, USA, www.systat.com) were used for all statistical analysis.

\section{Result}




\section{Clinical Characteristics of the Study Population}

The mean duration of diabetes was significantly higher in the group with heavy proteinuria compared to the groups with mild and no proteinuria respectively. The mean age, diastolic blood pressure, and fasting glucose of the group with heavy proteinuria are significantly higher compared to the group without proteinuria. The mean arterial pressure and systolic blood pressure of the heavy proteinuria group were significantly higher compared to the mild proteinuria group (Table 1).

\subsection{Frequency of Proteinuria in Relation to Body Mass Index}

The prevalence of proteinuria among the study respondents stratified by body mass index is as shown in Table 2. Out of the total of 32(4.7\%) underweight study participants, 62.5\% (20/490) had no proteinuria, $25 \%(8 / 98)$ had mild proteinuria and $12.5 \%(4 / 84)$ had heavy proteinuria. Out of the $274(40.2 \%)$ study participants with normal weight, $73.7 \%$ (202/490) had no proteinuria, 15.3\% (42/98) had mild proteinuria and $10.9 \%(15 / 47)$ had heavy proteinuria. For the $276(40.0 \%)$ pre-obese study participants,
208(75.4\%) had no proteinuria, 28 (10.1\%) had mild proteinuria and $40(14.5 \%)$ had heavy proteinuria. For the $100(14.7 \%)$ obese study participants, $60.0 \%(60 / 490)$ had no proteinuria with $20.0 \%$ each having mild (20/98) and heavy (20/94) proteinuria respectively.

\subsection{Determinants of Proteinuria in Relation to Fasting Blood Glucose}

Analyses of the frequency of proteinuria in relation to plasma fasting blood glucose concentration are as shown in Table 3. For the $86(12.6 \%)$ study participants with normal blood glucose concentration, $74.4 \%(64 / 490)$ had no proteinuria, $11.6 \%(10 / 98)$ had mild proteinuria and $14.0 \%$ (12/94) had heavy proteinuria. For the 96(14.1\%) study participants with impaired fasting glucose, $83.3 \%(80 / 490)$ had no proteinuria, $12.5 \%(12 / 98)$ had mild proteinuria and $4.2 \%$ (4/94) had heavy proteinuria. For the500 (73.3\%) study participants with fasting blood glucose greater $7.0 \mathrm{mmol} \mathrm{L}^{-1}$, $69.2 \%(346 / 490)$ had no proteinuria, $15.2 \%(76 / 98)$ had mild proteinuria and $15.6 \%(78 / 94)$ had heavy proteinuria (Table 3).

Table 1. Demographic, clinical and biochemical characteristics of the study participants stratified by the level of proteinuria on dipstick.

\begin{tabular}{|c|c|c|c|c|}
\hline Variable & $\begin{array}{c}\text { Total } \\
(\mathrm{n}=682)\end{array}$ & $\begin{array}{c}\text { None } \\
(\mathrm{n}=490)\end{array}$ & $\begin{array}{c}\text { Mild } \\
(\mathrm{n}=98)\end{array}$ & $\begin{array}{c}\text { Heavy } \\
(\mathrm{n}=94)\end{array}$ \\
\hline $\begin{array}{c}\text { Duration of diabetes } \\
\text { (years) }\end{array}$ & $5 \pm 4$ & $5.2 \pm 4.1$ & $6 \pm 5$ & $8 \pm 5^{* \dagger}$ \\
\hline Age (years) & $50 \pm 10$ & $48 \pm 10$ & $54 \pm 8$ & $100 \pm 12^{*}$ \\
\hline MAP & $94 \pm 10$ & $92 \pm 7$ & $97 \pm 15^{*}$ & $139 \pm 19^{*}$ \\
\hline SBP (mm Hg) & $130 \pm 14$ & $127 \pm 13$ & $134 \pm 14^{*}$ & $80 \pm 9 *$ \\
\hline DBP (mm Hg) & $76 \pm 7.0$ & $75 \pm 6$ & $77 \pm 7$ & $26 \pm 4$ \\
\hline BMI (kg m-2) & $25 \pm 4$ & $25 \pm 4$ & $25 \pm 5$ & $10 \pm 3^{*}$ \\
\hline $\begin{array}{c}\text { Fasting blood glucose } \\
(\mathrm{mmol} \mathrm{L-1})\end{array}$ & $9 \pm 4$ & $9 \pm 2$ & $9 \pm 3$ & \\
\hline
\end{tabular}

${ }^{*} \mathrm{p}<0.05 ; * *_{\mathrm{p}}<0.01 ; * * \mathrm{p}<0.001 ; *$ significantly different from group with no proteinuria; $\uparrow$ significantly different from group with mild proteinuria; MAP $=$ mean arterial pressure; $\mathrm{BMI}=$ body mass index; $\mathrm{SBP}=$ systolic blood pressure; DBP = diastolic blood pressure; None = negative; Mild = trace to 1+; Heavy $=2+$ to $4+$

Table 2. Determinants of proteinuria stratified by body mass index and the level of proteinuria on dip-stick.

\begin{tabular}{|c|c|c|c|c|}
\hline Body Mass Index & $\begin{array}{c}\text { Total } \\
(\mathrm{n}=682)\end{array}$ & $\begin{array}{c}\text { None } \\
(\mathrm{n}=490)\end{array}$ & $\begin{array}{c}\text { Mild } \\
(\mathrm{n}=98)\end{array}$ & $\begin{array}{c}\text { Heavy } \\
(\mathrm{n}=94)\end{array}$ \\
\hline Underweight $(<18.5)$ & $32(4.7)$ & $20(62.5)$ & $8(25.0)$ & $4(12.5)$ \\
\hline Normal $(18.5-24.9)$ & $274(40.2)$ & $202(73.7)$ & $42(15.3)$ & $30(10.9)$ \\
\hline Pre-obese $(25.0-29.9)$ & $276(40.0)$ & $208(75.4)$ & $28(10.1)$ & $40(14.5)$ \\
\hline Obese $(\geq 30.0)$ & $100(14.7)$ & $60(60.0)$ & $20(20.0)$ & $20(20.0)$ \\
\hline
\end{tabular}

Table 3. Frequency of proteinuria in relation to the level fasting blood glucose as well as the level of proteinuria on dipstick.

\begin{tabular}{|c|c|c|c|c|}
\hline Fasting blood glucose & $\begin{array}{c}\text { Total } \\
(\mathrm{n}=682)\end{array}$ & $\begin{array}{c}\text { None } \\
(\mathrm{n}=490)\end{array}$ & $\begin{array}{c}\text { Mild } \\
(\mathrm{n}=98)\end{array}$ & $\begin{array}{c}\text { Heavy } \\
(\mathrm{n}=94)\end{array}$ \\
\hline Normal $(<6.1)$ & $86(12.6)$ & $64(74.4)$ & $10(11.6)$ & $12(14.0)$ \\
\hline IFG $(\geq 6.1-<7.0)$ & $96(14.1)$ & $80(83.3)$ & $12(12.5)$ & $4(4.2)$ \\
\hline $\mathrm{DM}(>7.0)$ & $500(73.3)$ & $346(69.2)$ & $76(15.2)$ & $78(15.6)$ \\
\hline
\end{tabular}

$\mathrm{IFG}=$ impaired fasting glucose; $\mathrm{DM}=$ diabetes mellitus 


\subsection{Duration of diabetes and frequency of proteinuria}

Figure 1 assesses the frequency of proteinuria among the study participants in relation to the duration of diabetes. The frequency of heavy proteinuria showed a gradual increase from a frequency of $7.8 \%$ in study participants with diabetes duration of $<1$ year, through $8.1 \%$ (in the $1-5$ years diabetes duration group), $14.5 \%$ (in the $6-10$ years diabetes duration group), $33.3 \%$ (in the $11-15$ years diabetes duration group) and $60.0 \%$ in the $16-20$ diabetes duration group. None of the study participants with $>20$ years diabetes duration showed visible signs of heavy proteinuria. Mild proteinuria, from a frequency of $14.1 \%$ in participants with $<1$ year diabetes duration rose to $14.5 \%$ in the $1-5$ and $6-10$ years duration of diabetes groups respectively before gradually declining to $0.0 \%$ in the $16-20$ and $>20$ year duration of diabetes respectively. Generally, the frequency of no proteinuria in the study participants decreased gradually from $78.1 \%$ in the $<1$ year duration of diabetes group through $77.4 \%$ ( $1-5$ years), $70.0 \%$ (6- 10 years), $56.7 \%$ (11 - 15 -years), $40.0 \%$ (16- 20 years) and $33.3 \%$ ( $>20$ years).

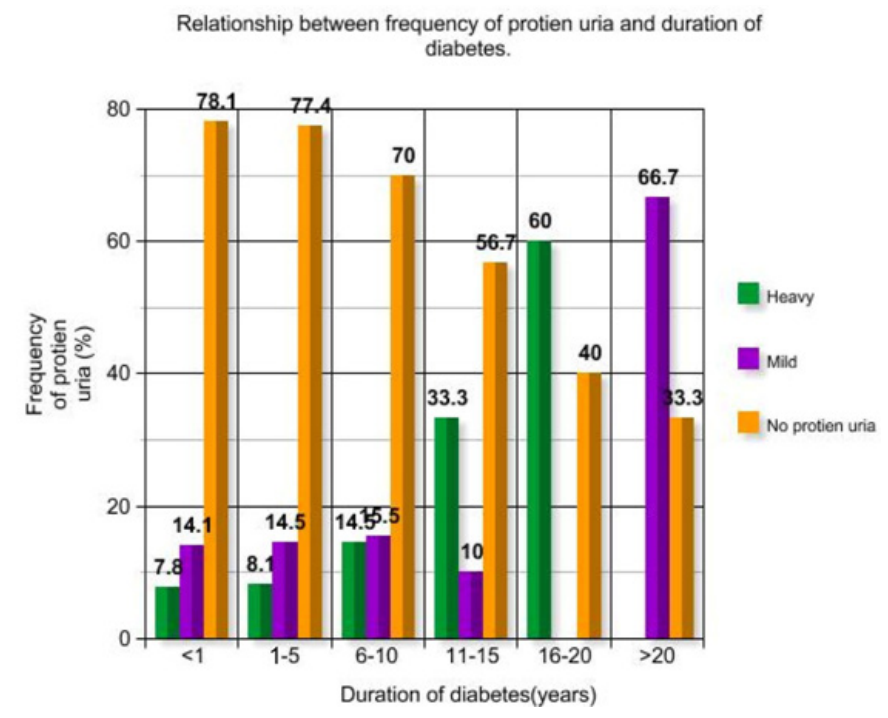

Figure 1. Relationship between frequency of protein urea and duration of diabetes.

\subsection{Blood pressure categories and frequency of proteinuria}

From Table 4, with the exception of $12(8.2 \%)$ study participants with optimal blood pressure who tested positive for heavy proteinuria, none of the study participants with normal blood pressure and pre-hypertension tested positive for heavy proteinuria.

Table 4. Frequency of proteinuria in relation to blood pressure categories as well as the level of proteinuria on dipstick.

\begin{tabular}{|c|c|c|c|c|c|c|}
\hline $\begin{array}{c}\text { Blood Pressure } \\
\text { Category }\end{array}$ & Systolic & Diastolic & $\begin{array}{c}\text { Total } \\
(\mathrm{n}=682)\end{array}$ & None & Mild & Heavy \\
\hline Optimal & $<120$ & $<80$ & $146(21.4)$ & $126(86.3)$ & $8(5.5)$ & $12(8.2)$ \\
\hline Normal & $120-129$ & $80-84$ & $16(2.3)$ & $14(87.5)$ & $2(12.5)$ & $0(0.0)$ \\
\hline Prehypertension & $130-139$ & $85-89$ & $16(2.3)$ & $10(62.5)$ & $6(37.5)$ & $0(0.0)$ \\
\hline \multicolumn{7}{|c|}{ Hypertension } \\
\hline Grade 1 & $140-159$ & $90-99$ & $24(3.5)$ & $12(50.0)$ & $4(16.7)$ & $8(33.3)$ \\
\hline Grade 2 & $160-179$ & $100-109$ & $0(0.0)$ & $0(0.0)$ & $0(0.0)$ & $0(0.0)$ \\
\hline Grade 3 & $\geq 180$ & $>110$ & $2(0.3)$ & $0(0.0)$ & $0(0.0)$ & $2(100.0)$ \\
\hline Isolated systolic & $\geq 140$ & $<90$ & $106(15.5)$ & $60(56.6)$ & $24(22.6)$ & $22(20.8)$ \\
\hline
\end{tabular}

There was a gradual increase in the frequency of participants with mild proteinuria from $5.5 \%$ in participants with optimal blood pressure through $12.5 \%$ for participants with normal blood pressure and $37.5 \%$ for participants with pre-hypertension. For the blood pressure categories, $86.3 \%$ of the participants with optimal blood pressure had no proteinuria; $87.5 \%$ of the participants with normal blood pressure had no proteinuria and $62.5 \%$ of the participants with pre-hypertension had no proteinuria. On grading hypertension, $33.3 \%$ of the participants with grade 1 hypertension had heavy Proteinuria, $16.7 \%$ had mild proteinuria and $50.0 \%$ had no proteinuria. The study participant with grade 3 hypertension had heavy proteinuria. Among the study participants with isolated systolic hyper-tension, $20.8 \%$ had heavy proteinuria, $22.6 \%$ had mild proteinuria and $56.6 \%$ had no proteinuria. 


\subsection{Odds analysis of some selected variables and their association with proteinuria.}

Multivariate logistic regression analysis of selected variables and their association with proteinuria are as shown in Table 5. Sex was not significantly associated with proteinuria. Testing positive for urine glucose was associated with approximately 2 times risk of testing positive for proteinuria $(\mathrm{OR}=1.9 ; \mathrm{p}=0.023)$. On the analysis of $\mathrm{BP}$, systolic $(\geq 140 \mathrm{~mm} \mathrm{Hg})$ and diastolic $(\geq 90 \mathrm{~mm} \mathrm{Hg}$ ) blood pressure were both linked with 3 times risk for proteinuria $(\mathrm{p}=0.000$ and $\mathrm{p}=0.019$ respectively). Analysis of age categories for the participants showed a marginal risk for proteinuria within the $41-48$ year age group (OR $=4.4 ; \mathrm{p}=0.051)$ and the 57-64year age group $(\mathrm{OR}=5.5 ; \mathrm{p}=0.053)$ respectively. The 49-56year age group however showed a significant association with proteinuria with a 7.2 times risk $(\mathrm{p}=0.010)$. The fasting blood glucose concentration of the participants was not significantly associated with proteinuria. Stratification of the study participants by BMI showed no significant association between the classes of BMI and proteinuria $(\mathrm{p}>0.05)$. On analyzing diabetes duration however, periods from $11-15$ years and $16-20$ years were linked with a significant presence of proteinuria with odds ratios of 2.8 and 5.6 respectively.

Table 5. Multivariate logistic regression of factors associated with proteinuria

\begin{tabular}{|c|c|c|c|}
\hline Variables & OR $(95 \% \mathrm{CI})$ & $P$ value & SE \\
\hline \multicolumn{4}{|c|}{ Gender } \\
\hline Female* & 1 & & \\
\hline Male & $1.2(0.7-1.9)$ & 0.597 & 0.304 \\
\hline MAP & $1.1(1.0-1.1)$ & 0.000 & 0.015 \\
\hline \multicolumn{4}{|c|}{ Urine glucose } \\
\hline Positive & $1.9(1.1-3.2)$ & 0.023 & 0.506 \\
\hline \multicolumn{4}{|c|}{$\mathrm{BP}(\mathrm{mm} \mathrm{Hg})$} \\
\hline Systolic $(\geq 140)$ & $3.0(1.8-5.2)$ & 0.000 & 0.833 \\
\hline Diastolic $(\geq 90)$ & $3.0(1.2-7.8)$ & 0.019 & 1.453 \\
\hline \multicolumn{4}{|c|}{ Age (years) } \\
\hline $25-32 *$ & 1 & & \\
\hline $33-40$ & $3.8(0.8-17.6)$ & 0.089 & 2.971 \\
\hline $41-48$ & $4.4(1.0-19.6)$ & 0.051 & 3.356 \\
\hline $49-56$ & $7.2(1.6-32.7)$ & 0.010 & 5.574 \\
\hline $57-64$ & $5.5(1.0-31.5)$ & 0.053 & 4.908 \\
\hline$\geq 65$ & --- & ----- & ----- \\
\hline \multicolumn{4}{|c|}{ Fasting Glucose $\left(\mathrm{mmol} \mathrm{L}^{-1}\right)$} \\
\hline$<6.1 *$ & 1 & & \\
\hline \multirow{2}{*}{$\begin{array}{c}6.1-7.0 \\
>7.0\end{array}$} & $1.0(0.3-3.4)$ & 0.976 & 0.623 \\
\hline & $1.8(0.6-5.5)$ & 0.330 & 1.024 \\
\hline \multicolumn{4}{|c|}{$\operatorname{BMI}\left(\mathrm{kg} \mathrm{m}^{-2}\right)$} \\
\hline Underweight* & 1 & & \\
\hline Normal & $0.7(0.2-2.2)$ & 0.572 & 0.418 \\
\hline Pre-obese & $0.7(0.2-2.1)$ & 0.486 & 0.388 \\
\hline Obese & $1.3(0.4-4.5)$ & 0.642 & 0.826 \\
\hline \multicolumn{4}{|c|}{ Diabetes duration (years) } \\
\hline$<1^{*}$ & 1 & & \\
\hline $1-5$ & $1.1(0.5-2.2)$ & 0.839 & 0.401 \\
\hline $6-10$ & $1.6(0.8-3.3)$ & 0.186 & 0.590 \\
\hline $11-15$ & $2.8(1.1-7.2)$ & 0.028 & 1.351 \\
\hline $16-20$ & $5.6(1.4-22.5)$ & 0.016 & 3.968 \\
\hline$>20$ & $7.4(0.6-88.0)$ & 0.112 & 9.369 \\
\hline
\end{tabular}

* Reference variables; $\mathrm{OR}=$ odds ratio; $\mathrm{CI}=$ confidence interval; $\mathrm{SE}=$ standard error of the odds ratio estimates; $\mathrm{MAP}=$ mean arterial pressure; $\mathrm{BP}$ $=$ blood pressure 


\section{Discussion}

This study evaluated the effects of blood pressure, obesity, fasting blood glucose concentration, duration of diabetes and age on the frequency of proteinuria among type 2 diabetics. The degree of proteinuria increased with advancing age, blood pressure and the duration of the diabetes. Such significant association with proteinuria (appearance of protein in urine) therefore presents each of the assessed variables as independent risk factors to the development of nephropathy (kidney damage).

The observed association between heavy proteinuria and the mean duration of diabetes among study participants from this study corroborates similar observations made in numerous studies and confirms duration of diabetes as an important factor in the development of proteinuria (Klein et al., 1995; Stratton et al., 2000).

Several studies have identified male gender and older age of onset of diabetes as independent risk factors for proteinuria in T2DM (Ballard et al., 1988; Gall et al., 1991; Klein et al., 1995). From this study, sex and for that matter being a male was not a significant risk factor for proteinuria as observed from the multivariate logistic regression analysis. However, older age of onset, specifically age $\geq 50$ years was significantly associated with proteinuria. It therefore suffices to infer from the results that irrespective of sex, age of onset of T2DM greatly modifies the presence or absence of proteinuria.

Elevated blood pressure, be it systolic or diastolic was significantly associated with proteinuria and in previous studies has been found to be an independent risk factor for the development and progression of proteinuria in T2DM (Rossing et al., 2004). Hypertensive nephrosclerosis has been identified as the foremost cause of end stage kidney disease (USRD, 1999). Consequently, treatment with has been shown to reduce the risk of developing proteinuria and also slowing down the progression of renal injury once nephropathy develops (Parving, 1998). A further stratification of the study participants by grade of hypertension showed increases in mild and heavy proteinuria as hypertensive grade increased. The anti-hypertensive proteinuria risk reduction could however not be assessed in this study cohort as per the design of the study, information on anti-hypertensive treatment was not sought. The finding of $15.5 \%$ of the study participants with ISH is consistent with previously published works (Trevisan et al., 2002; Bakris, 2004) and could be due to the fact that type 2 diabetic patients are mostly burdened with ISH.

The estimated proteinuria prevalence among the obese participants reported in this study is far lower than that reported from the work of Alwakeel et al., (2011). The observed difference could be attributed to the methodology adapted for proteinuria estimation. In this study, proteinuria was assessed using early morning urine whilst in the study of Alwakeel et al., (2011) proteinuria was assessed utilizing 24 hour urine.

The high rate of obesity with its associated high proteinuria (mild and heavy) observed in this study is in conformity with the findings of (Praga and Morales, 2006). Weight loss, thus, has been identified as an inducer of a reduction in proteinuria among patients with varied causes of proteinuria for which weight gain is an attributable risk factor

Obesity, hypertension and duration of diabetes independently contribute to the development of proteinuria in T2DM. Elevated BMI has been recognized as a risk factor for increased proteinuria among diabetics in several studies (Anastasio et al., 2000; Ramirez et al., 2002) however no significant association was observed in the classes of BMI and proteinuria from the multivariate analysis conducted in this study. BMI has been touted as being an insensitive method for assessing adiposity and this fact coupled with dietary therapy and restriction in this cohort of study participants could account for the lack of an observed significant difference in the BMI classes and proteinuria. The effect of hyperglycemia on proteinuria is well documented (Stratton et al., 2000). Fasting glucose concentration was not significantly associated with proteinuria from the multivariate analysis in this study but duration of diabetes $(11-20$ years $)$ was significantly associated with proteinuria. The $15 \%$ frequency of heavy proteinuria found in participants with elevated FBS levels in this study could thus be attributed to good glycemic control practices among this cohort of participants" couples with a reduced duration of diabetes which could be the sole deciding factor. A number of studies (Ramirez et al., 2002; Al-Homrany and Abdelmoneim, 2004) have observed using logistic regression models that those with high SBP and DBP besides longer duration of diabetes have higher levels of proteinuria. This finding is corroborated by results from this study. From the multivariate analysis, the above named factors individually contribute to kidney damage through glomerulosclerosis ultimately resulting in hyper filtration and consequently proteinuria, which is a cardinal sign of overt nephropathy.

\section{Conclusion}

From the result it can be concluded that the frequency of proteinuria at Shakiso health center with T2DM was $13.8 \%$. Significant predictors of proteinuria included like age, obesity, duration of diabetes and hyper-tension. Strategies to mitigate the occurrence of nephropathy should be targeted at glycemic and hypertension control.

\section{Acknowledgements}

I am very grateful to the participants and staff of health center. 


\section{REFERENCES}

[1] Al-Homrany, MA, Abdelmoneim, I [2004] Significance of proteinuria in type 2 diabetic patients treated at a primary health care center in Abha City, Saudi Arabia. West Afr J Med 23[3]: 211-214.

[2] Alwakeel, JS, Isnani, AC, Alsuwaida, A, Alharbi, A, Shaffi, SA, Almohaya, S, Al Ghonaim, M [2011] Factors affecting the progression of diabetic nephropathy and its complications: a single-center experience in Saudi Arabia. Ann Saudi Med 31[3]: 236-242.

[3] Anastasio, P, Spitali, L, Frangiosa, A, Molino, D, Stellato, D, Cirillo, E, Pollastro, RM, Capodicasa, L, Sepe, J, Federico, P, Gaspare De Santo, N [2000] Glomerular filtration rate in severely overweight normotensive humans. Am J Kidney Dis 35[6]: 1144-1148.

[4] Bakris, GL [2004]the importance of blood pressure control in the patient with diabetes. Am J Med 116 Suppl 5A: 30S-38S

[5] Ballard, DJ, Humphrey, LL, Melton, LJ, 3rd, Frohnert, PP, Chu, PC, O'Fallon, WM, Palumbo, PJ[1988] Epidemiology of persistent proteinuria in type II diabetes mellitus. Population-based study in Rochester, Minnesota. Diabetes 37[4]: 405-412.

[6] Balogun, WO, Abbiyesuku, FM [2011] Excess renal insufficiency among type 2 diabetic patients with dip-stick positive proteinuria in a tertiary hospital. Afr $\mathrm{J}$ Med MedSci40[4]: 399-403.

[7] Chobanian, AV, Bakris, GL, Black, HR, Cushman, WC, Green, LA, Izzo, JL, Jr., Jones, DW, Materson, BJ, Oparil, S, Wright, JT, Jr., Roccella, EJ[2003]

The Seventh Report of the Joint National Committee on Prevention, Detection, Evaluation, and Treatment of High Blood Pressure: the JNC 7 report. JA-MA 289[19]: 2560-2572.

[8] Gall, MA, Rossing, P, Skott, P, Damsbo, P, Vaag, A, Bech, K, Dejgaard, A, Lauritzen, M, Lau-ritzen, E, Hougaard, P, et al. [1991] Prevalence of micro- and macro albuminuria, arterial hypertension, retinopathy and large vessel disease in European type 2 (non-insulin-dependent) diabetic patients. Diabetologia34[9]: 655-661. Harris, M, Zimmet, P [eds] [199]

[9] Classification of diabetes mellitus and other categories of glucose intol-erance. John Wiley and Sons Ltd: Chichester.

[10] Imai, E, Matsuo, S, Makino, H, Watanabe, T, Akizawa, T, Nitta, K, Iimuro, S, Ohashi, Y, Hishida, A [2008] Chronic Kidney Disease Japan Cohort [CKD-JAC] study: esign and methods. Hypertens Res 31[6]: 1101-1107.

[11] Kirkendall, WM, Burton, AC, Epstein, FH, Freis, ED [1967] Recommendations for human blood pressure determination by sphygmomanometers. Circulation 36[6]: 980-988.

[12] Klahr, S, Levey, AS, Beck, GJ, Caggiula, AW, Hun-sicker, L, Kusek, JW, Striker, G[1994] The effects of dietary protein restriction and blood-pressure control on the progression of chronic renal disease. Modification of Diet in Renal Disease Study Group. N Engl J Med 330[13]: 877-884.

[13] Klein, R, Klein, BE, Moss, SE, Cruickshanks, KJ [1995]Ten-year incidence of gross proteinuriain people with diabetes. Diabetes 44 [8]: 916-923.

[14] Leehey, DJ, Kramer, HJ, Daoud, TM, Chatha, MP, Isreb, MA [2005] Progression of kidney disease in type 2 diabetes - beyond blood pressure control: an observational study. BMC Nephrol6: 8 .

[15] Lutale, JJ, Thordarson, H, Abbas, ZG, Vetvik, K [2007]Micro albuminuria among Type 1 and Type 2 diabetic patients of African origin in Dar Es Salaam, Tanzania. BMC Nephrol8: 2.

[16] Mandal, AK, Hiebert, LM [2008] Renal protection in diabetes: is it affected by glucose control or inhibition of the renin-angiotensin path-way? ClinNephrol [3]:169-178.

[17] Parving, HH (1998) Reno protection in diabetes: genetic and non-genetic risk factors and treatment. Diabetologia41[7]: 745-759.

[18] Peterson, JC, Adler, S, Burkart, JM, Greene, T, Hebert, LA, Hunsicker, LG, King, AJ, Klahr, S, Massry, SG, Seifter, JL [1995] Blood pressure control, proteinuria, and the progression of renal disease. The Modification of Diet in Renal Disease Study. Ann Intern Med 123:[10]754-762.

[19] Praga, M, Morales, E [2006] Weight loss and proteinuria. ContribNephrol151: 221-229.

[20] Ramirez, SP, McClellan, W, Port, FK, Hsu, SI [2002] Risk factors for proteinuria in a large, multiracial, Southeast Asian population. J Am SocNephrol13[7]: 1907-1917.

[21] Rossing, K, Christensen, PK, Hovind, P, Tarnow, L, Rossing, P, Parving, HH[2004] Progression of nephropathy in type 2 diabetic patients. Kidney Int66 [4]: 1596-1605.

[22] Stratton, IM, Adler, AI, Neil, HA, Matthews, DR, Manley, SE, Cull, CA, Hadden, D, Turner, RC, Holman, RR [2000] Association of glycaemia with macro vascular and microvascular complications of type 2 diabetes [UKPDS35]: prospective observational study. BMJ 321[7258]: 405-412.

[23] Trevisan, R, Vedovato, M, Mazzon, C, Coracina, A, Iori, E, Tiengo, A, Del Prato, S [2002] Concomitance of diabetic retinopathy and proteinuria accelerates the rate of decline of kidney function in type 2 diabetic patients. Diabetes Care 25 [11]: 2026-2031.

[24] Trinder, P [1969] Determination of blood glucose using 4-amino phenazone as oxygen acceptor. J ClinPathol22[2]: 246.

[25] USRD [1999] Annual Data Report United States Renal Data System: Incidence and prevalence of ESRD. , Health, NIo [ed], pp 25- 38. Bethany, MD.: National Institute of Diabetes and Digestive and Kidney Diseases

[26] USRD[2004] United States Renal Data System web-site; http//www.usrd.org/adr.htm Annual data report 2004. 